\title{
Association Between Vertebrobasilar Insufficiency and Cervicogenic Headache: Hypothetical Approach Towards Etiopathogenesis of Headache
}

\author{
Aninditya Kaur ${ }^{1}$, N. Rakesh ${ }^{2}$, Sujatha S. Reddy ${ }^{3}$, Nithin Thomas ${ }^{4}$, Ravleen Nagi ${ }^{5}$, Deepa Jatti Patil ${ }^{6}$ \\ 'DMD Imaging, Gurgaon, India \\ ${ }^{2}$ Department of Oral Medicine and Radiology, Faculty of Dental Sciences, M.S. Ramaiah University of Applied Sciences, \\ Bangalore, India \\ ${ }^{3}$ Department of Oral Medicine and Radiology, M.S. Ramaiah University of Applied Sciences, Bangalore, India \\ ${ }^{4}$ Maxillofacial Diagnostics, Cochin, India \\ ${ }^{5}$ Department of Oral Medicine and Radiology, Swami Devi Dyal Hospital and Dental College, Panchkula, India \\ ${ }^{6}$ Department of Oral Medicine and Radiology, KM Shah Dental College and Hospital, Sumandeep Vidyapeeth Deemed to be \\ University, Vadodara, India
}

Received August 14, 2020

Revised September 30, 2020

Accepted October 12, 2020

Correspondence to:

N. Rakesh

Department of Oral Medicine and Radiology, Faculty of Dental Sciences, M.S. Ramaiah University of Applied Sciences, Bangalore, Karnataka 560054, India

Tel: $+91-8045366666$

Fax: $+91-804536677$

E-mail:drnrakesh@gmail.com

https://orcid.org/0000-0003-4388-6334
Purpose: Cervicogenic headache (CGH) is pain referred to the head/ face from the structures in vicinity of upper cervical spinal nerves via trigeminocervical pathway. Ponticulus Posticus (PP) and Elongated Styloid Process (ESP) are anatomical structures that cause compression of vasculature present around upper cervical nerve plexus. Recently, computational fluid dynamics (CFD) has shown to play an essential role in identification of these highpressure zones in the brain. The aim of this research is to study the association of ESP and PP in patients with CGH and to develop a hypothesis by CFD to analyse vertebrobasilar insufficiency as a contributing factor in occurrence of CGH.

Methods: Retrospective analysis of 4500 full skull CBCT scans was done for the presence of partial or complete PP and length of Styloid Process (SP). Research was divided into two phases; In first Preliminary Phase, 150 scans that showed the presence of PP and ESP were analysed, and only 134 patients gave consent to fill the questionnaire containing 96 question items pertaining to symptoms associated with CGH. In the second phase, simulation of Vertebral and Carotid Artery was done using Fluent 14.5 Software and by CFD, pressure distribution on arteries was obtained that helped to identify high pressure regions.

Results: Both PP and ESP showed a statistically significant association with CGH $(\mathrm{p}<0.001)$. By CFD analysis, both steady and transient phases of simulation showed drop in pressure due to constriction of internal carotid and vertebral artery by ESP and PP respectively and were found to decrease the volume of blood reaching the brain, $0.12 / 0.13 \mathrm{~mL}$ and $0.06 \mathrm{~mL}$ respectively.

Conclusions: Our analysis proves ESP and PP as contributing factors towards CGH. Hence for proper diagnosis and management of headache disorders, clinicians should have adequate knowledge about these anatomical structures and their resulting clinical symptoms.

Key Words: Blood flow; Cervicogenic headache; Computational fluid dynamics; Ponticulus posticus; Styloid process; Vertebral artery

Copyright (c) 2020 Korean Academy of Orofacial Pain and Oral Medicine. All rights reserved.

(c) This is an open-access article distributed under the terms of the Creative Commons Attribution Non-Commercial License (http://creativecommons.org/licenses/by-nc/4.0/), which permits unrestricted non-commercial use, distribution, and reproduction in any medium, provided the original work is properly cited. 


\section{INTRODUCTION}

Headache is common and most disabling disorder affecting more than $66 \%$ of the world's population, but is often misdiagnosed and not treated properly [1]. According to World Health Organisation, headache is one of the top ten causes of disability and more commonly manifests in women with a stressful lifestyle at home and at work place [2]. According to International Headache Society (IHS) there are 2 basic categories of headaches, i) primary headaches of vascular (cluster and migraine headaches) and muscular origin (tension-type headaches), ii) secondary headaches that occur because of another health condition [2]. Norwegian physician Sjaastad and Bakketeig [3] coined the term, "cervicogenic headache" (CGH) in 1983, a type of secondary headache as it originates from the atlanto-occipital and upper cervical vertebrae and perceived in one or more regions of head. The prevalence rate of CGH is $2.5 \%$ to $4.1 \%$, which is comparatively lower than tension-type headache (38\%), migraine (10\%), and chronic daily headache (3\%). However, it is most distressing of all, affecting daily routine activities and causes serious impact on the quality of life of patients [3].

The characteristic features of CGH given by the IHS also known as "Red Flags" include i) headache associated with neck pain and stiffness; ii) unilateral headaches starting from one side of the posterior head and neck, migrating to the front, and sometimes associated with ipsilateral arm discomfort; iii) deep, nonthrobbing, moderate to severe pain which may be continuous or intermittent lasting for hours to days; iv) Pain triggered by neck movement, abnormal neck postures, exertion, coughing, and by applying digital pressure around upper cervical C1-C3 or occipital areas [4].
There could be a possibility that cases of CGH could be misdiagnosed as primary headache disorders such as migraine or tension type headache due to overlapping features like nausea, dizziness, ipsilateral neck, shoulder or arm pain, radiating to forehead, temples, orbital region, vertex or ear, ipsilateral blurred vision, and lacrimation leading to improper treatment without patient relief.

Recently researchers have found that abnormalities in cerebral blood flow due to increased pressure from anatomical structures like ponticulus posticus (PP) and elongated styloid process (ESP) may result in CGH [5-10]. PP also known as "little posterior bridge", "Kim merle variant", "foramen arcuale" is an anomalous bony bridge formed between superior articular process and posterior arch of atlas. It is regarded as a simple anatomical variant formed by complete or incomplete ossification of the posterior atlanto-occipital membrane over the vertebral groove that results in development of arcuate foramen containing vertebral artery and C1 spinal nerve (Fig. 1A-C) [10]. Fig. 2 illustrates partial and complete PP on three-dimensional (3D) printed models. Compression of these structures has been found to result in severe headache in 56\% to 96\% of patients [10-12]. Styloid process (SP) is an elongated conical projection of the temporal bone, present anteriorly to the mastoid process. The normal SP length is approximately $20-30 \mathrm{~mm}$ and is considered elongated if it is longer than $30 \mathrm{~mm}$ (Fig. 1D). Symptoms due to ESP are seen rarely, prevalent in 4\% to $10 \%$ of population [13]. Compression of neurological structures such as glossopharyngeal nerve and vascular structures such as external and internal carotid artery by ESP or medial or lateral deviation of SP results in "stylocarotid syndrome" which is characterized by neck pain aggravated
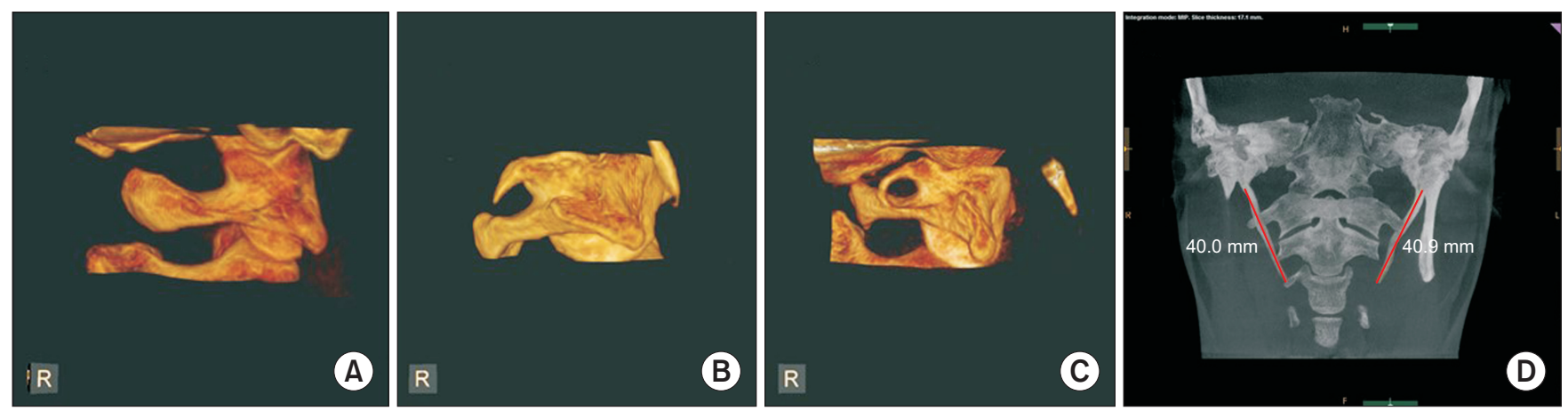

Fig. 1. Cone beam computed tomography scan depicting ponticulus posticus, (A) absent; (B) partial; (C) complete (D) elongated styloid process. 

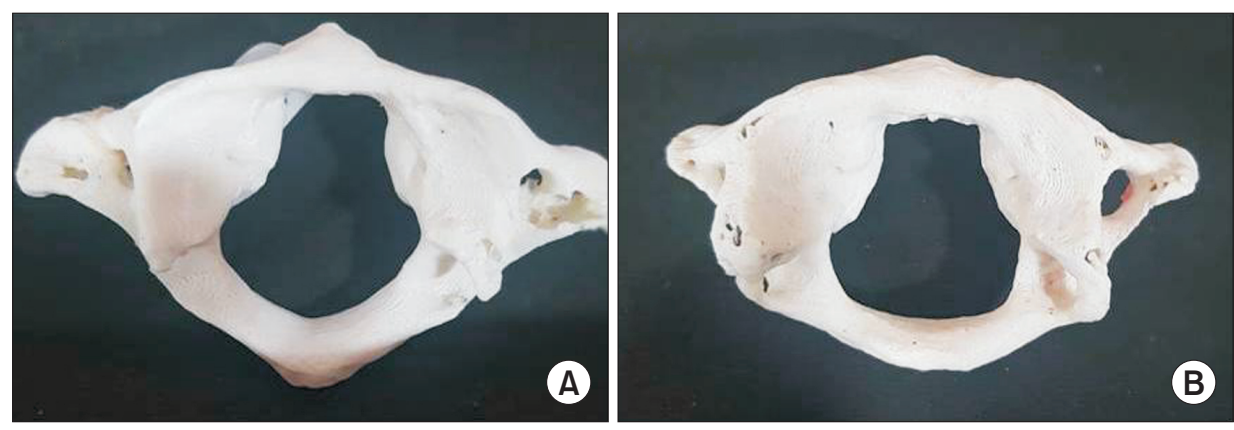

Fig. 2. Three-dimensional printed models $(A)$ partial ponticulus posticus (PP) C1 vertebra (B) complete PP vertebra.

by rotation of neck, decreased blood flow to brain, and headache . Impingement of internal carotid artery causes supraorbital pain and parietal headache whereas impingement of external carotid artery results in pain radiating to infraorbital region [14].

Panoramic radiography, computed tomography (CT) and magnetic resonance imaging (MRI) have been found to have limited role in diagnosis of anatomical or vascular structures as a cause of CGH, they could be used as a primary imaging modalities to suspect underlying secondary cause of headache $[15,16]$. Nowadays three-dimensional cone beam computed tomography (3D CBCT) has been shown to have high diagnostic accuracy in demonstration and measurement of both anatomical structures; ESP and PP but has limited ability in detection of vascular structures [6]. Recently, computational fluid dynamics (CFD) algorithms, image processing and geometry reconstruction techniques has been reported to have high diagnostic performance in computing for neurovascular disorders [17]. CFD is two types-static/steady and transient state, the basic difference is that unlike static, transient CFD simulates time-dependent changes in the motion of fluid and is more accurate.

By this research we tried to develop hypothesis by adoption of computational methods to analyse if anatomical structures; ESP and PP could result in fluid dynamic changes [17]. Therefore, to elucidate this concept, research was conducted in the Department of Oral Medicine and Radiology to prove the association of ESP and PP with CGH. Our research was divided into two phases; i) In the first preliminary phase $\mathrm{CBCT}$ scans were retrospectively analysed for the presence or absence of ESP and PP. Then, validated questionnaire adapted from Fritsche et al. [18] and Hong et al. [19] was given to patients after their informed consent to evaluate CGH symptoms; ii) In the second phase a real life like simulation was performed with the help of CFD to analyse vertebrobasilar insufficiency due to ESP or PP.

\section{MATERIALS AND METHODS}

\section{Preliminary Research}

1) Evaluation of CBCT Images

A retrospective study was conducted in the Department of Oral Medicine and Radiology, M.S. Ramaiah Dental College, Bangalore on CBCT (Carestream 9300; Carestream Health, Rochester, NY, USA) images of patients who have been referred for CBCT examination for various problems of maxillofacial region such as partially edentulous area assessment requiring implants, for the assessment of malocclusion, temporomandibular joint disorders, etc. Exclusion criteria comprised inadequate image quality due to artifacts; low resolution; and patient movement during exposure. CBCT images showing presence of neoplastic tumour, congenital anomalies such as cleft lip and palate, and systemic abnormalities involving the craniofacial region were excluded. Analysis was done for 4500 CBCT full skull scans using Dell liquid crystal display screen with a resolution of $1,280 \times 1,024$ pixels. Images were adjusted for contrast and brightness by software tools and reconstructed into 3D images. Out of 4500 full skull scans, 150 scans demonstrating PP and SP were retrieved and analysed visually under adequate illumination by 10 year experienced radiologist for the length and angulations of SP as well as for the presence of complete or partial PP. It was found that out of 150 scans of the subjects, ESP was present in 142, PP was present in 60 and both ESP and PP were present in 52 scans. SP was analysed in three planes i.e. axial, coronal and sagittal planes for following parameters: 
(1) Length: It is distance between the base of the SP and the tip of the ossified stylohyoid complex. SP with length $\geq 30 \mathrm{~mm}$ [20] was considered as elongated (Fig. 1D).

(2) Mediolateral angulation: Measured by the angle of intersection of the line connecting both bases of the SP and the longitudinal axis of stylohyoid complex on anteroposterior view (Fig. 3A) [20].

(3) Horizontal anteroposterior angulation: A vertical line was passed from the cranial base of the process, vertical to Frankfort plane (a line passing horizontally from the superior border of external auditory meatus to the inferior border of orbit). Anterior angulation is measured as the angle between this vertical line on lateral skull X-ray and the body of the process (Fig. 3B) [20].

(4) Vertical anteroposterior angulation: Anteroposterior angle was defined as the vertical line passing from the cranial base of the process, which was vertical to the Frankfort plane (a line passing horizontally from the superior border of the external auditory meatus to the inferior border of orbit) on the lateral view. The angle between this vertical line and the body of the process was measured (Fig. 3B) [20].

(5) Lateral or medial curvature: The angle between the base of the SP and the tip of the stylohyoid complex at the level of the bending point on skull base views (Fig. 3C) [20].

\section{2) Questionnaire}

CBCT analysis was followed by customized questionnaire [adapted from Fritsche et al. [18] and Hong et al. [19] that was given for validation to i) two (2) senior professors having 20 years of experience in oral medicine, ii) two (2) senior professors having 20 years of experience in oral radiology, and two (2) senior professors having 20 years of experience in otorhinolaryngology. Specialists' opinions were included and questionnaire was further validated with Cronbach's alpha with a value of 0.85 which is quite reliable.

Questionnaire consisted of 96 question items given to 150 subjects with an age range of 15 to 86 years, it consisted of both open and closed ended questions pertaining to CGH symptoms, that is its nature, type, intensity and duration, any associated symptoms, vision abnormalities, itchiness or watery discharge from eyes, or any abnormalities in the ear. 150 subjects whose CBCT scans showed presence of ESP, that is $\geq 30 \mathrm{~mm}$ or presence of partial or complete PP were distributed questionnaire through telephone interviews, by mail, online, or through direct physical distribution after obtaining informed consent. Patients who presented with history of suspected diagnosis or treatment of neoplastic tumour, congenital and systemic abnormalities of craniofacial region formed the exclusion criteria. Based on selection criteria and on patients consent, out of 150 distributed questionnaires, only 134 respondents including 86 males (64.2\%) and 48 females (35.8\%) filled the questionnaire. Thereafter, completed questionnaires were analysed in relation to association of CGH symptoms with ESP length, anteroposterior (horizontal and vertical) angulations, mediolateral angulations and medial or lateral curvature as depicted on their respective $\mathrm{CBCT}$ images.

\section{3) Statistical Analysis}

Data collected was statistically analyzed using SPSS Statistics for Windows, Version 16.0 (SPSS Inc., Chicago, IL,
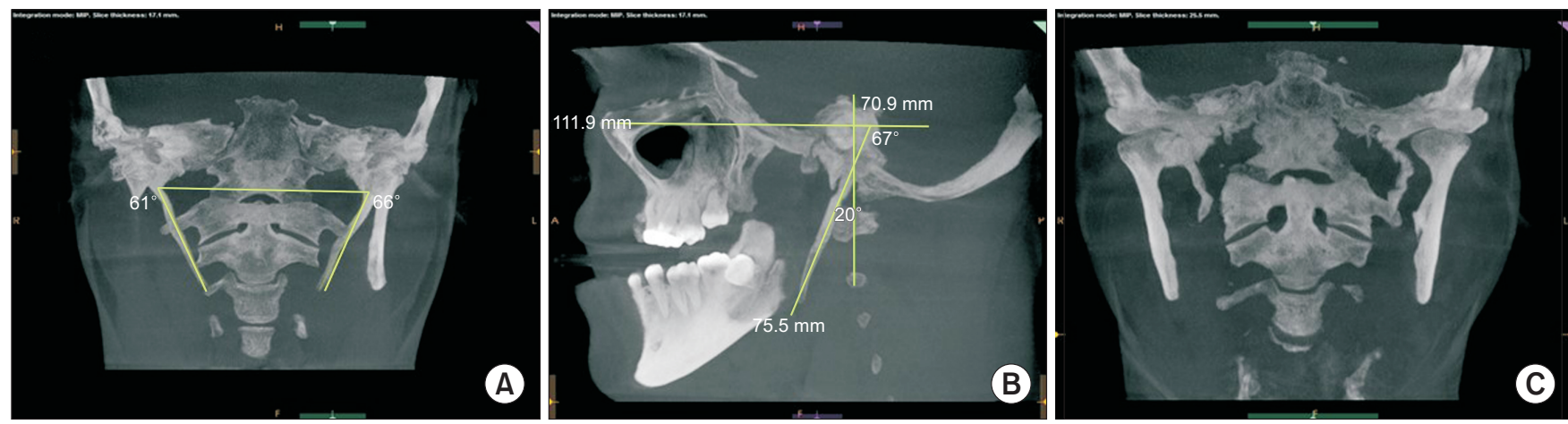

Fig. 3. Elongated styloid process (A) mediolateral angulation, (B) anteroposterior angulation (horizontal \& vertical), (C) medial or lateral curvature. 
USA). Contingency table was formulated to display the frequency distribution of 134 subjects that showed presence of ESP, PP, or both on CBCT images and presence or absence of CGH based on responses as mentioned in questionnaire. A chi-square test was applied to analyze the association between the anatomical structures and CGH. Association of SP parameters i.e length, mediolateral angulation, anteroposterior angulation (horizontal \& vertical) and lateral or medial curvature with CGH was done by Pearson's correlation test. A $p<0.05$ was considered as statistically significant.

\section{Phase II Hypothetical Model and Analysis: CFD simulation}

CT angiography (arterial) image of patient diagnosed with haemangioma of lip, extending from the arch of aorta up to the brain was retrieved from the archives of Department of Radiodiagnosis, M.S. Ramaiah Medical Hospital (Fig. 4A)

CFD was performed in five basic steps i) medical image registration, ii) automatic segmentation and reconstruction of the radiographic images using open end software 3D Slicer version 4.6.2 (Slicer Community, Boston, MA, USA; http://www.slicer.org) [21] that converted medical image from .dcm to .stl format to form in-silico model (Fig. $4 \mathrm{~B})$. Further refining of the model was done using software Meshmixer version 3.0 (Open end software, Oakland, CA, USA) so as to crop the region of interest to be used in simulation (Fig. 4C) by ten-year experienced radiologist. This entire procedure took approximately 4-5 hours, iii) meshing or spatial discrimination i.e. model clean-up was done and required geometry was extracted using Mimics software 20.0 (Materialise NV Company, Leuven, Belgium) (Fig. 5A). This entire process of conversion took approximately 1-2 days, iv) boundary conditions were applied and v) finally
CFD simulation. Final model was made up of approximately 20 lakh grid cells across the whole artery. Fig. 5B depicts final geometries used for simulation.

\section{1) Simulation of Blood Flow and Pressure Changes}

For simulating blood flow and pressure changes caused due to the presence of ESP and PP on internal carotid and vertebral artery, respectively the cross-sections of both the arteries were modified by giving constriction around the point that was designated as ESP1 and PP2. This was considered as the location of probable ESP and PP respectively (Fig. 6A, B), that is there is high chance or likelihood of compression of vasculature by anatomical structures, this assumption was verified by performing steady and transient state simulation . At this location, SP is in close proximity to external and internal carotid arteries, and PP is in close relation to vertebral artery. Blood is considered as
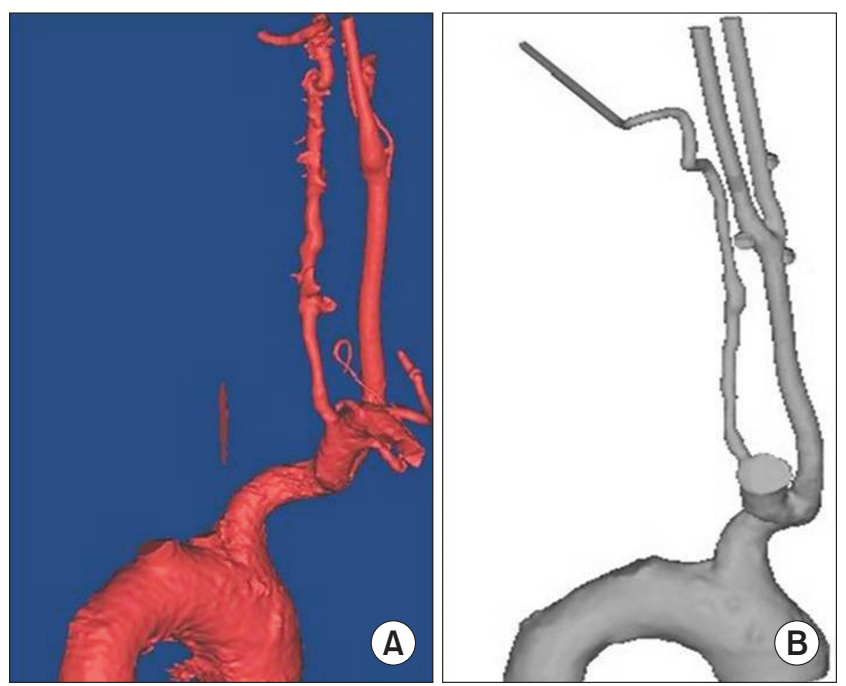

Fig. 5. (A) Extraction of required geometry using mimics software. (B) Final geometries used for simulation.
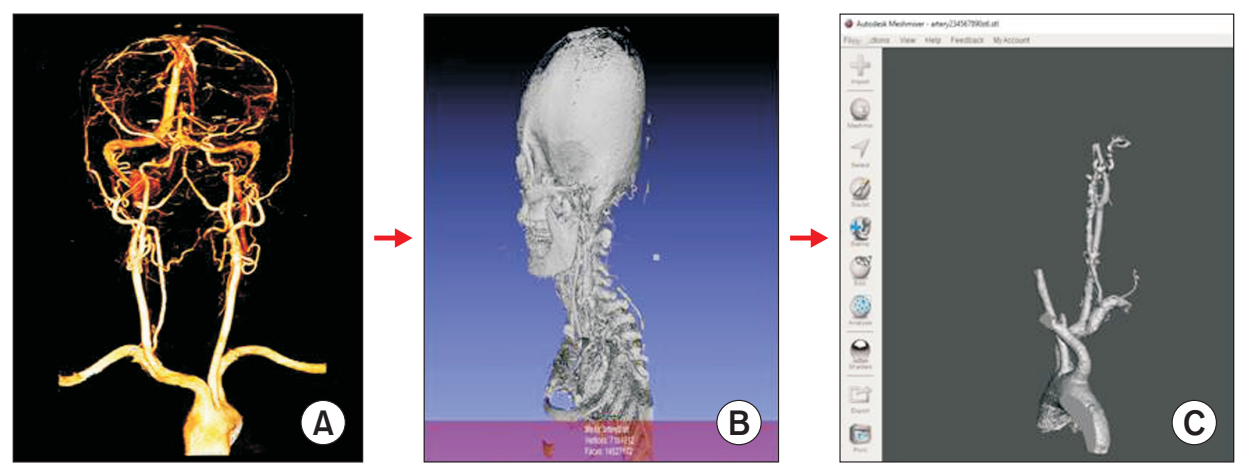

Fig. 4. Model construction (A) computed tomography-angiography arterial phase, (B) conversion of image from . $\mathrm{dcm}$ to. $\mathrm{stl}$ by open end software, three-dimensional Slicer 4.6.2, and (C) meshmixer 3.0 (Open end software, Oakland, CA, USA) cropped region of interest. 
Newtonian fluid with density of $1,060 \mathrm{~kg} / \mathrm{m}^{3}$ and viscosity of $0.035 \mathrm{~kg} / \mathrm{m}$-s. Thus, the final model comprised of one inlet and four outlets (Fig. 7).

CFD simulation was done in both static steady and transient state. For static steady state, simulation was performed under normal physiological condition and in situation where vasculature was compressed by ESP and PP as under:

(1) Static steady state simulation: For static simulation inlet was considered as pressure inlet and outlet as pressure outlet. The CFD software used for steady state simulation

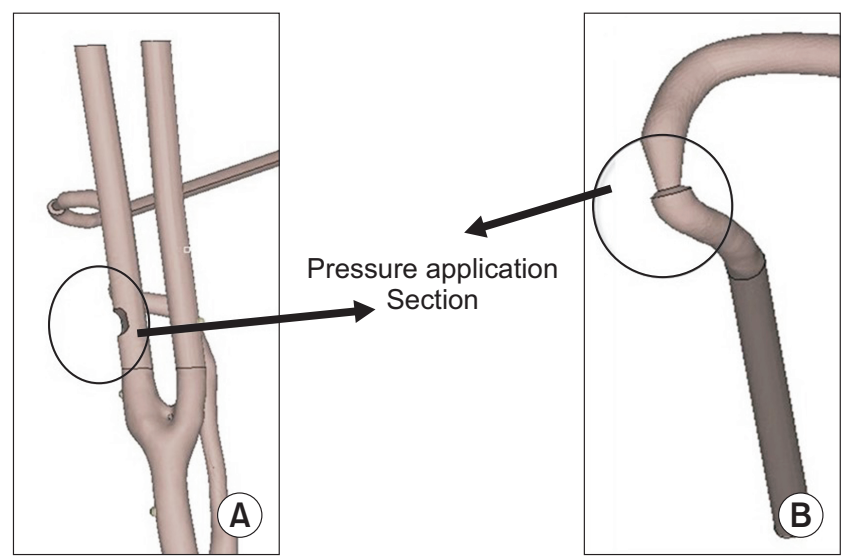

Fig. 6. (A) Modification on cross-section on carotid artery at the site of probable elongated styloid process. (B) Modification on cross-section on vertebral artery at the site of probable ponticulus posticus. was United States based open end software Ansys Fluent Solver version 14.5 (Ansys Inc., Canonsburg, PA, USA). Simulation was done under normal physiologic conditions under inlet pressure of $120 \mathrm{~mm}$ (normal systolic pressure) and $60 \mathrm{~mm}$ of $\mathrm{Hg}$ (normal diastolic pressure) at the arch of aorta which was taken as reference point (Fig. 8A). Drop-in

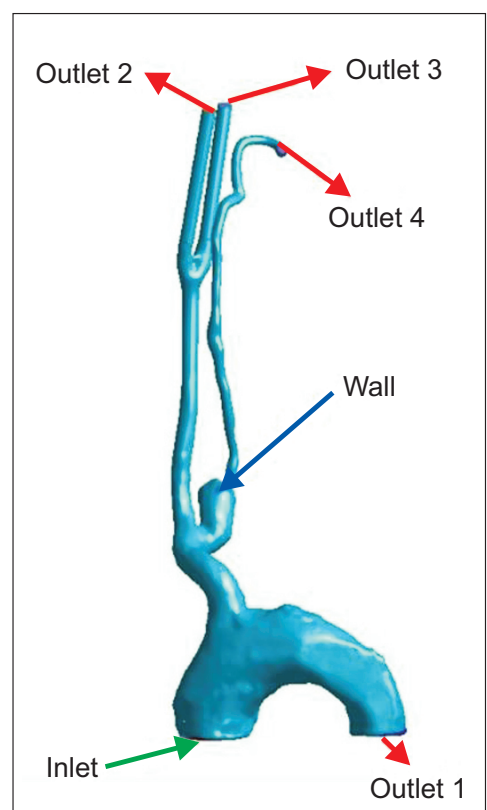

Fig. 7. Shows final model composed of one inlet and four outlets by United States based open end software, Ansys Fluent Solver version 14.5 .
A

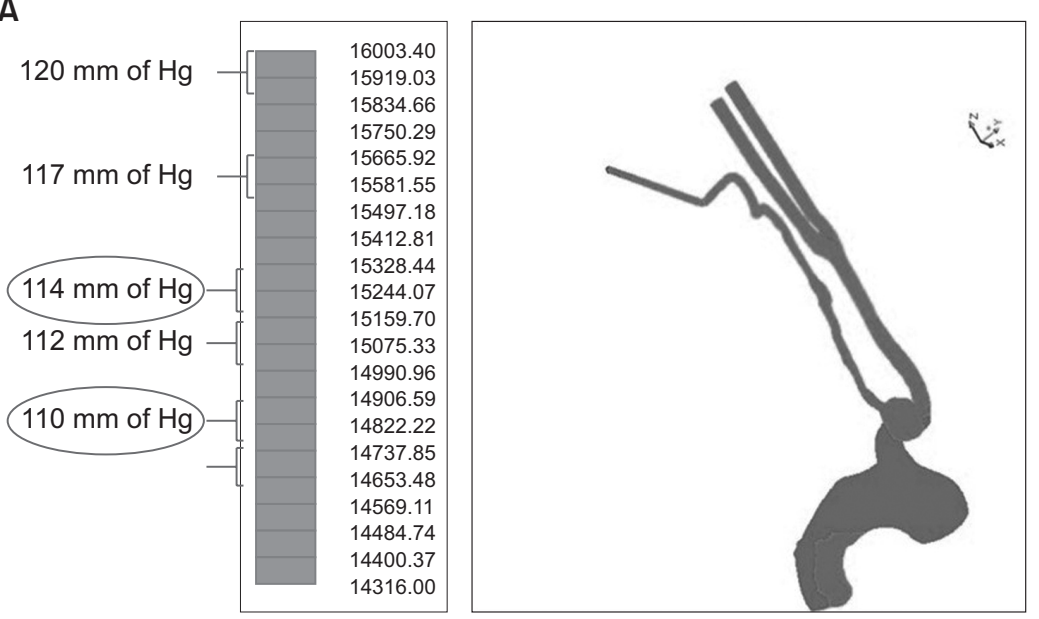

B

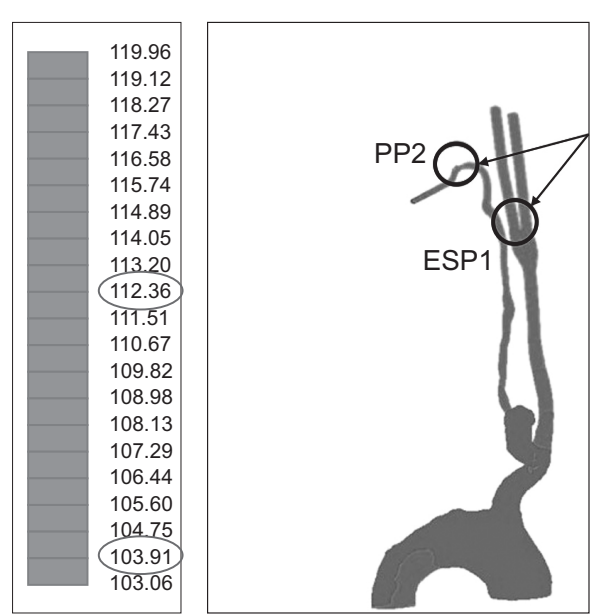

Contours of static pressure in pascals

Fig. 8. Steady state simulation using United States based open end software, Ansys Fluent Software 14.5 (A) inlet pressure at $120 \mathrm{mmHg}$ under normal physiologic conditions (B) inlet pressure at $120 \mathrm{mmHg}$ after constriction of vasculature by ESP and PP. ESP, elongated styloid process; PP, ponticulus posticus; ESP1, pressure point at location of probable ESP; PP2, pressure point at location of probable PP. 
pressure was measured from arch of aorta and upwards till the point of constriction of vasculature i.e. till ESP1 and PP2 (Fig. 8B).

(2) Transient state simulation: Since steady state simulation could not predict time dependent variation of pressure as well as changes in the blood volume, hence to be more accurate and specific we moved one step ahead i.e. towards transient simulation. The CFD software used for transient state simulation was Semi Implicit Method for Pressure Linked Equation, developed by Prof. Brian Spalding, London, United Kingdom. Inlet was kept as mass flow inlet calculated based on the velocity as a function of time and outlet as pressure outlet. The total number of time steps solved were 80 in a total time of 0.8 seconds i.e. one cardiac cycle and maximum and minimum flow velocity of blood was $0.9 \mathrm{~m} / \mathrm{s}$ and $0.05 \mathrm{~m} / \mathrm{s}$, respectively.

For transient simulation range of blood pressure varied from 90/60 $\mathrm{mm}$ of $\mathrm{Hg}$ till 120/90 $\mathrm{mm}$ of $\mathrm{Hg}$ and variation in blood pressure as well as volume was measured for 0.8 seconds. Variation of blood pressure and flow was measured from arch of aorta up to the three points for 0.8 seconds i.e. p1, p2 and p3 on both internal carotid artery and vertebral artery. p1 was considered as the point just before constriction by ESP and PP; p2 was the point of constriction and p3 was the point after constriction (Fig. 9).

Descriptive statistics was used to summarize the numerical values showing variation in blood pressure and volume on simulation.

\section{RESULTS}

\section{Results: Preliminary Research}

On summation of analysis it was found that out of 134 subjects, comprising of 86 males (64.2\%) and 48 females (35.8\%) with an age range of 15 to 86 years, 114 showed the presence of ESP (102 bilateral \& 12 unilateral ESP) and 48 had PP (27 bilateral \& 21 unilateral PP). Out of 114 ESP subjects, 47 subjects (41.2\%) presented with headache and 67 subjects (58.8\%) did not. Among 48 subjects with PP, 46 subjects (95.8\%) had headache and 2 subjects (4.2\%) did not. Thus, the results showed a significant association of individual osseous structures with headache $(\mathrm{p}<0.001)$ (Table 1). Individual SP parameters i.e length, mediolateral angulation, anteroposterior angulation (horizontal \& vertical) and lateral or medial curvature demonstrated no statistically significant association with CGH (Table 2). To simulate this hypothesis in a real-life situation we took a step forward towards CFD. This was done to analyse how ESP and PP can cause pressure changes in the vascular structures of head and neck region resulting in vertebrobasilar insufficiency ultimately leading to CGH.

\section{Results: CFD Simulation}

\section{1) Steady State Simulation}

(1) Normal physiologic conditions: Results showed that under normal physiologic conditions there was a significant

Table 1. Table shows association of ESP and PP with headache

\begin{tabular}{lcc}
\hline Parameter & $\begin{array}{c}\text { Total no. of subjects } \\
\text { with ESP or PP }\end{array}$ & $\begin{array}{c}\text { Total no of subjects } \\
\text { having headache }\end{array}$ \\
\hline ESP & $114(98.22)[2.54]^{\mathrm{a}}$ & $47(62.78)[3.97]$ \\
PP & $48(57.35)[1.52]$ & $46(36.65)[2.38]$ \\
Both ESP+PP & $32(38.43)[1.09]$ & $31(24.57)[1.69]$ \\
\hline
\end{tabular}

ESP, elongated styloid process; PP, ponticulus posticus. abserved count (expected count) [chi square $\chi^{2}$ statistic], $\chi^{2}$ value 13.1698.

Statistically significant difference $(p=0.001)$.

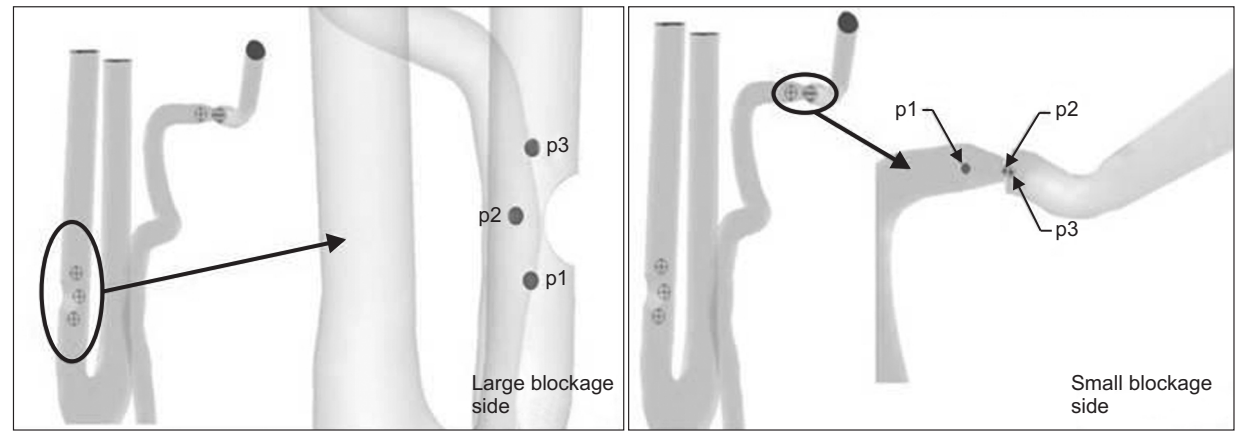

Fig. 9. Points specified to observe pressure changes under transient simulation. 
Table 2. Association of CGH with ESP length, anteroposterior (horizontal \& vertical) angulations, mediolateral angulations and medial or lateral curvature

\begin{tabular}{|c|c|c|c|c|c|}
\hline ESP parameter & $\mathrm{CGH}$ & Mean & Standard deviation & Standard error mean & p-value \\
\hline \multirow[t]{2}{*}{ Right ESP length (mm) } & Present & 37.58 & 13.99 & 2.04 & 0.33 \\
\hline & Absent & 38.33 & 15.60 & 1.85 & \\
\hline \multirow[t]{2}{*}{ Left ESP length (mm) } & Present & 35.97 & 13.51 & 1.99 & 0.34 \\
\hline & Absent & 38.70 & 15.44 & 1.83 & \\
\hline \multirow[t]{2}{*}{ Right ESP anterior vertical angle $\left(^{\circ}\right)$} & Present & 30.87 & 7.10 & 1.03 & 0.42 \\
\hline & Absent & 31.54 & 7.58 & 0.89 & \\
\hline \multirow[t]{2}{*}{ Right ESP anterior horizontal angle $\left(^{\circ}\right)$} & Present & 62.20 & 5.67 & 0.83 & 0.96 \\
\hline & Absent & 61.70 & 6.02 & 0.71 & \\
\hline \multirow[t]{2}{*}{ Left ESP anterior vertical angle $\left(^{\circ}\right)$} & Present & 31.14 & 6.76 & 0.98 & 0.89 \\
\hline & Absent & 31.19 & 7.35 & 0.67 & \\
\hline \multirow[t]{2}{*}{ Left ESP anterior horizontal angle $\left(^{\circ}\right)$} & Present & 62.65 & 6.14 & 0.90 & 0.65 \\
\hline & Absent & 62.40 & 5.95 & 0.70 & \\
\hline \multirow[t]{2}{*}{ Right ESP medial angle $\left(^{\circ}\right)$} & Present & 66.51 & 5.27 & 0.76 & 0.79 \\
\hline & Absent & 69.06 & 4.54 & 0.60 & \\
\hline \multirow[t]{2}{*}{ Left ESP medial angle $\left(^{\circ}\right)$} & Present & 69.06 & 4.54 & 0.66 & 0.28 \\
\hline & Absent & 66.92 & 8.93 & 1.06 & \\
\hline
\end{tabular}

CGH, cervicogenic headache; ESP, elongated styloid process.

Table 3. Steady-state simulation at $120 \& 60 \mathrm{~mm}$ of $\mathrm{Hg}$ inlet pressure at arch of aorta

\begin{tabular}{lcc}
\hline \multicolumn{1}{c}{ Vascular structures } & $\begin{array}{c}\text { Pressure under normal } \\
\text { physiologic conditions }\end{array}$ & $\begin{array}{c}\text { Pressure after constriction } \\
\text { by osseous structures }\end{array}$ \\
\hline At $120 \mathrm{~mm}$ of $\mathrm{Hg}$ inlet pressure at arch of aorta & & $112 \mathrm{~mm} \mathrm{of} \mathrm{Hg}$ \\
ESP1 (pressure point at the location of ESP) & $114 \mathrm{~mm}$ of Hg \\
PP2 (pressure point at the location of PP) & $110 \mathrm{~mm}$ of Hg & $104 \mathrm{~mm}$ of Hg \\
At $60 \mathrm{~mm}$ of Hg inlet pressure at arch of aorta & $58 \mathrm{~mm}$ of Hg & $56 \mathrm{~mm}$ of Hg \\
ESP1 (pressure point at the location of ESP) & $51 \mathrm{~mm}$ of Hg & $48 \mathrm{~mm}$ of Hg \\
PP2 (pressure point at the location of PP) &
\end{tabular}

ESP, elongated styloid process; PP, ponticulus posticus.

pressure drop from arch of aorta towards ESP1 and PP2 at $120 \mathrm{~mm}$ of $\mathrm{Hg}$ and $60 \mathrm{~mm}$ of $\mathrm{Hg}$ pressure. When the inlet pressure was $120 \mathrm{~mm}$ of $\mathrm{Hg}$ the pressure at ESP1 was 114 $\mathrm{mm}$ of $\mathrm{Hg}$ and at PP2 was $110 \mathrm{~mm}$ of $\mathrm{Hg}$. Thus from the reference point i.e. arch of aorta the drop in pressure occurred by $6 \mathrm{~mm}$ of $\mathrm{Hg}$ at ESP1 and $10 \mathrm{~mm}$ of $\mathrm{Hg}$ at PP2. Similar results were found when the inlet pressure was 60 $\mathrm{mm}$ of $\mathrm{Hg}$ (Table 3). From the arch of aorta the pressure reduced to $58 \mathrm{~mm}$ of $\mathrm{Hg}$ at ESP1 and $51 \mathrm{~mm}$ of $\mathrm{Hg}$ at PP2.

(2) Vasculature constriction: After constriction of internal carotid artery by ESP and vertebral artery by PP, it was found that when inlet pressure was $120 \mathrm{~mm}$ of Hg, pressure at ESP 1 reduced to $112 \mathrm{~mm}$ of $\mathrm{Hg}$ and by $104 \mathrm{~mm}$ of $\mathrm{Hg}$ at PP2. From arch of aorta, drop in pressure occurred by $8 \mathrm{~mm}$ of $\mathrm{Hg}$ at ESP1 and by $16 \mathrm{~mm}$ of $\mathrm{Hg}$ at PP2 (Table 4). Similar results were observed for inlet pressure $60 \mathrm{~mm}$ of $\mathrm{Hg}$, from the arch of aorta pressure at ESP1 reduced to 56 $\mathrm{mm}$ of $\mathrm{Hg}$ and at PP2 it was $48 \mathrm{~mm}$ of $\mathrm{Hg}$.

\section{2) Transient State Simulation}

(1) Variation in blood pressure: Firstly, simulation was done keeping the blood pressure as 90/60 $\mathrm{mm}$ of $\mathrm{Hg}$ and under normal physiologic conditions it was found that from the arch of aorta up to the internal carotid artery the pressure at p1, p2, p3 was $69 \mathrm{~mm}$ of $\mathrm{Hg}, 68.6 \mathrm{~mm}$ of $\mathrm{Hg}, 68.4$ $\mathrm{mm}$ of $\mathrm{Hg}$ respectively and after constriction of internal carotid artery by ESP the variation of pressure at p1 was 69.5 $\mathrm{mm}$ of $\mathrm{Hg}$, at $\mathrm{p} 2$ the pressure reduced to $67.8 \mathrm{~mm}$ of $\mathrm{Hg}$ and at p3 it was $67.6 \mathrm{~mm}$ of $\mathrm{Hg}$. Similarly from the arch of aorta up to the vertebral artery the pressure at p1, p2, p3 under normal physiologic conditions was 71.8, 71.2, 71.2 $\mathrm{mm}$ of $\mathrm{Hg}$ respectively and after constriction of vertebral artery by PP the pressure changes at p1, p2, p3 was 77.8, 69, and 67 $\mathrm{mm}$ of $\mathrm{Hg}$ respectively (Table 4). Likewise simulation was 
Table 4. Pressure variation in transient Simulation due to ESP and PP at $90 / 60 \mathrm{~mm}$ of $\mathrm{Hg} \&$ at $120 / 90 \mathrm{mmHg}$

\begin{tabular}{|c|c|c|c|}
\hline $90 / 60 \mathrm{~mm}$ of $\mathrm{Hg}$ & $\mathrm{p} 1$ & $\mathrm{p} 2$ & p3 \\
\hline \multicolumn{4}{|l|}{ Due to ESP } \\
\hline Normal case & $69 \mathrm{~mm}$ of $\mathrm{Hg}$ & $68.6 \mathrm{~mm}$ of $\mathrm{Hg}$ & $68.4 \mathrm{~mm}$ of $\mathrm{Hg}$ \\
\hline Constriction at internal carotid artery by ESP & $69.5 \mathrm{~mm}$ of $\mathrm{Hg}$ & $67.8 \mathrm{~mm}$ of $\mathrm{Hg}$ & $67.6 \mathrm{~mm}$ of $\mathrm{Hg}$ \\
\hline \multicolumn{4}{|l|}{ Due to PP } \\
\hline Normal case & $71.8 \mathrm{~mm}$ of $\mathrm{Hg}$ & $71.2 \mathrm{~mm}$ of $\mathrm{Hg}$ & $71.2 \mathrm{~mm}$ of $\mathrm{Hg}$ \\
\hline Constriction at vertebral artery by PP & $77.8 \mathrm{~mm}$ of $\mathrm{Hg}$ & $69 \mathrm{~mm}$ of $\mathrm{Hg}$ & $67 \mathrm{~mm}$ of $\mathrm{Hg}$ \\
\hline $120 / 90 \mathrm{~mm}$ of $\mathrm{Hg}$ & $\mathrm{p} 1$ & p2 & p3 \\
\hline \multicolumn{4}{|l|}{ Due to elongated styloid process } \\
\hline Normal case & $103 \mathrm{~mm}$ of $\mathrm{Hg}$ & $102.6 \mathrm{~mm}$ of $\mathrm{Hg}$ & $102.5 \mathrm{~mm}$ of $\mathrm{Hg}$ \\
\hline Constriction at internal carotid artery by ESP & $103.5 \mathrm{~mm}$ of $\mathrm{Hg}$ & $101.9 \mathrm{~mm}$ of $\mathrm{Hg}$ & $101.7 \mathrm{~mm}$ of $\mathrm{Hg}$ \\
\hline \multicolumn{4}{|l|}{ PP } \\
\hline Normal case & $105.8 \mathrm{~mm}$ of $\mathrm{Hg}$ & $105.2 \mathrm{~mm}$ of $\mathrm{Hg}$ & $105.2 \mathrm{~mm}$ of $\mathrm{Hg}$ \\
\hline Constriction at vertebral artery by PP & $112 \mathrm{~mm}$ of $\mathrm{Hg}$ & $103 \mathrm{~mm}$ of $\mathrm{Hg}$ & $101 \mathrm{~mm}$ of $\mathrm{Hg}$ \\
\hline
\end{tabular}

ESP, elongated styloid process; PP, ponticulus posticus.

p1 point just before constriction by ESP and PP; p2 point of constriction and p3 point after constriction.

done at the blood pressure of 120/90 mm of $\mathrm{Hg}$, under normal physiologic conditions the pressure from arch of aorta till internal carotid artery at p1, p2, p3 was $103 \mathrm{~mm}$ of $\mathrm{Hg}$, $102.6 \mathrm{~mm}$ of $\mathrm{Hg}, 102.5 \mathrm{~mm}$ of $\mathrm{Hg}$ respectively and from arch of aorta till vertebral artery the pressure values were 105.8, 105.2 and $105.2 \mathrm{~mm}$ of $\mathrm{Hg}$ at p1, p2, p3 respectively. The variation in pressure caused due to constriction of internal carotid artery by ESP at p1, p2, p3 was 103.5, 101.9 and $101.7 \mathrm{~mm}$ of $\mathrm{Hg}$ and constriction of vertebral artery by PP caused pressure variation of 112, 103 and $101 \mathrm{~mm}$ of $\mathrm{Hg}$ at p1, p2, p3 respectively (Table 4). Results showed that at p2 which was the point of constriction there was significant pressure drop in both cases i.e. at 90/60 $\mathrm{mm}$ of $\mathrm{Hg}$ the reduction in pressure caused by ESP and PP was 0.8 and 2.2 $\mathrm{mm}$ of $\mathrm{Hg}$ respectively (Table 4). When the pressure was 120/90 $\mathrm{mm}$ of $\mathrm{Hg}$ the drop in pressure was 0.7 and $2.2 \mathrm{~mm}$ of Hg due to ESP and PP respectively (Table 4). Thus more or less similar variation of pressure was found in both the cases.

(2) Variation in blood volume: With the help of pressure variation values, corresponding variation in the volume of blood was also calculated. It was found that ESP caused a reduction of $0.13 \mathrm{~mL}$ of blood to the brain when the blood pressure was $90 / 60 \mathrm{~mm}$ of $\mathrm{Hg}$ and this reduction was 0.12 $\mathrm{mL}$ at a pressure of $120 / 90 \mathrm{~mm}$ of $\mathrm{Hg}$. The reduction in amount of blood reaching the brain caused by the presence of PP was $0.06 \mathrm{~mL}$ for both 90/60 and 120/90 mm of $\mathrm{Hg}$ (Table 5). All these changes were calculated for one cardiac
Table 5. Pressure and volume variation in transient simulation due to ESP and PP at $90 / 60$ \& $120 / 90 \mathrm{~mm}$ of $\mathrm{Hg}$

\begin{tabular}{lcc}
\hline \multicolumn{1}{c}{ Parameter } & $90 / 60 \mathrm{~mm}$ of Hg & $120 / 90 \mathrm{~mm}$ of Hg \\
\hline ESP & & \\
Pressure changes & $0.8 \mathrm{~mm}$ of $\mathrm{Hg}$ & $0.7 \mathrm{~mm}$ of Hg \\
Volume & $0.13 \mathrm{~mL}$ in $0.8 \mathrm{~s}$ & $0.12 \mathrm{~mL}$ in $0.8 \mathrm{~s}$ \\
Changes & $14 \mathrm{~L}$ in $24 \mathrm{~h}$ & $13.7 \mathrm{~L}$ in $24 \mathrm{~h}$ \\
PP & & \\
Pressure changes & $2.2 \mathrm{~mm}$ of Hg & $2.2 \mathrm{~mm}$ of Hg \\
Volume & $0.06 \mathrm{~mL}$ in $0.8 \mathrm{~s}$ & $0.06 \mathrm{~mL}$ in $0.8 \mathrm{~s}$ \\
Changes & $10 \mathrm{~L}$ in $24 \mathrm{~h}$ & $10 \mathrm{~L}$ in $24 \mathrm{~h}$ \\
\hline
\end{tabular}

ESP, elongated styloid process; PP, ponticulus posticus.

cycle i.e. 0.8 seconds. On further calculating the reduction in amount of blood reaching the brain due to ESP and PP in a day i.e. 24 hours it was found to be approximately 14 litres which was quite significant.

\section{DISCUSSION}

Headache disorders are often under diagnosed, and considered as conditions of low medical importance and they could be a symptom of serious underlying disorder [1]. Most often the clinicians fail to diagnose the condition precisely, thereby depriving the patient from appropriate treatment which further worsens the condition and could seriously affect the patient's quality of life both professionally and socially. In a recent study done on 90,000 adults to analyse the capabilities of health professionals in accurately diagnosing the headache, the researchers showed that 
approximately 70\% of the patients were under diagnosed, $24 \%$ were diagnosed as primary, and $6 \%$ as secondary headaches thus reflecting the lack of optimum knowledge among general practitioners in diagnosing such conditions $[1,2]$.

Cervical spine is an unexplored area, often overlooked by the specialists in identifying the cause of headache. CGH is pain referred to unilateral temporal, occipital and frontal regions from the cervical structures innervated by upper three cervical spinal nerves via trigeminocervical nucleas [5]. CGH is aggravated by neck movements and by applying digital pressure over the tender points in the cervical region [14]. Diagnostic features of this headache are limited, and are often misdiagnosed as migraine or tension headache which could result in persistent head and neck pain affecting daily activities of the patient. Etiopathogenesis of CGH is a debatable topic. Of all chronic headaches, it is most distressing unilateral headache, four times more common in middle aged females and patient in most cases gives history of whiplash injury, head and neck trauma and may occur due to musculoskeletal dysfunction of neck [6]. Watson and Trott [8], in 1993 first noted that forward head posture could aggravate the symptoms of CGH as it increases stress on the upper cervical segments. Over a few years, clinical researchers have implied that structures centred on $\mathrm{C}$, C2, and C3 spinal levels can be the source of referred pain to head. Trigeminocervical nucleus that descends from the spinal cord to level of $\mathrm{C} 3 / 4$ is in anatomical and functional continuity with dorsal grey columns of these segments and is considered as widely accepted mechanism by which pain is directly referred to head [6,9]. According to Bogduk [5], there is convergence of nociceptive afferents from the upper three spinal nerves $\mathrm{C} 1$ to $\mathrm{C} 3$ and the trigeminal nerve located in trigeminocervical nucleus . Due to this convergence, there is bidirectional referral of painful sensations between receptive fields present in upper cervical segments and the receptive fields of trigeminal nerve innervating head and face.

Researchers have implicated that anatomical bony structures in the head and neck region mainly ESP and PP could result in CGH $[6,7,9]$. Arcuate Foramen is least understandable anatomical anomaly of the atlas vertebrae, first described by Kimmerle in 1930. Variety of synonyms exist for arcuate foramen in the literature such as PP, foramen retroarticulare superior, canalis vertebralis, retroarticular vertebral artery ring, retroarticular canal and retrocondylar vertebral artery ring [11]. Several controversial theories have been proposed for the origin of PP, some believe it to be an congenital or genetic trait, or it may be the result of an ossification caused by age or presence of an external mechanical factors such as carrying heavy loads on the head could lead to development of this bony bridge. It has been hypothesized that this PP could compress the calibre of the vertebral artery resulting in cerebral ischemia and chronic headache symptoms provoked by neck rotation [20]. Similarly another osseous structure studied to compress the vasculature is ESP, described by Eagle in 1937 as "stylocarotid syndrome" in which stylohyoid complex exerts pressure on the external and internal carotid arteries, thus stimulating the sympathetic nerve fibres lying in vicinity of carotid arteries resulting in unilateral headache, orbital pain, and recurrent syncope triggered by movement or rotation of neck $[13,14]$.

Literature studies have demonstrated significant association of ESP and PP with CGH $[7,12,15]$. They have suggested that close proximity of SP to carotid artery and PP to vertebral artery, causes compression of these vascular structures resulting in vertebrobasilar insufficiency and cervicofacial pain /or headache. Wight et al. [12] studied the relationship of PP and headache symptoms, and significant association was found between PP and unilateral headache. PP is closely attached to the atlanto-occipital membrane which is further attached to the dura. Thus any mechanical trauma at the atlanto-occipital joint could cause traction of the dura, resulting in onset of unilateral headache. Tambawala et al. [15] found overall prevalence of CGH in 6\% of patients and suggested PP as a cause of unexplainable headache, neck pain and other associated symptoms. In a case study by Chuang et al. [6] CT and angiography of the neck showed ESP abutting the left internal carotid artery, resulting in cerebral ischemia of the left side. Apart from the length, improper angulation of the SP can also cause cervicofacial pain/headache. Oztunc etal [7] corroborated that reduced medial angulation of SP resulted in significant orofacial pain although the length of SP was normal.

Complete history followed by clinical and neurological examination is required to diagnose the patients with 
orofacial pain symptoms. Clinician should examine the patient with unilateral cephalgia with neck pain according to diagnostic criteria proposed by IHS. Laboratory evaluation may be done to rule out any systemic disease that may adversely affect bone, joint and muscles. In addition, anaesthetic nerve blockade is considered as a confirmatory test, but could not identify the underlying cause of headache such as compression of neurovascular structures by the both osseous structures i.e. ESP and PP [22,23]. Oral radiologists can play a valuable role by diagnosing these both osseous structures by radiographic examination, but conventional radiographs such as panoramic, lateral cephalogram, Towne view provide limited diagnostic information due to magnification and superimposition of anatomical structures. Diagnostic modalities such as two-dimensional CT scan, MRI could not reveal exact position of the anatomical structures and also overestimates the exact length of SP. Our study used 3D CBCT images that demonstrates anatomical relationships of osseous structures in the head and neck region like ESP and PP with higher accuracy, but CBCT has limited ability in differentiation of soft tissue structures like blood vessels etc [24]. Over few years, CFD, is gaining popularity as new diagnostic modality for neurovascular disorders. Therefore, we elucidated this concept by performing CFD which showed that both of these structures could cause compression of vasculature resulting in decreased cerebral blood flow and symptoms of severe headache and neck pain.

CFD is a well-established tool used by bioengineers to study complex physiological blood flows and to build complex computer representations (in silico models) of the cardiovascular system in health and disease [25]. Studies have revealed that CFD has been used in various research areas such as investigation of blood flow in the external carotid artery and its branches, and provides functional imaging of the arteries of heart $[17,26]$. To our knowledge this is a first study conducted which can be a foot forward in proving the clinical association of different osseous and neurovascular structures with CGH and significant association of ESP and PP was observed with CGH ( $p=0.001)$ Results of CFD simulation suggested that there is decrease in blood pressure and volume from the reference point i.e arch of aorta due to constriction of vertebral and carotid artery by
ESP and PP respectively, in both steady and transient phases of simulation. These pressure and volume variations result in decreased cerebral blood flow and subsequent CGH.

Preventive and therapeutic measures can be initiated at an early stage in such patients to improve their quality of life. Since inappropriate use of non-prescribed self-medications can cause more harm than good as patients usually develop tolerance to these medications, hence there is a strong need to modify therapeutic modalities from pharmacologic to non-pharmacologic measures [27]. Spinal manipulative therapy to the cranio vertebral articulation is an effective alternative treatment, other non-pharmacologic means include strengthening exercises of the cervical spine, thrust to thoracic spine, forward posture correction etc [28]. A study by Jull and Stanton [29] reported that a six-week physiotherapy program including manual therapy and exercise interventions was an effective treatment option for reduction of CGH symptoms and decreasing medication intake in both short term and at one year follow-up.

For CFD applications it is unclear how detailed the clinical data needs to be in terms of geometry (segmented from medical images) and parameterisation (variability described by the model and the tuning of patient-specific boundary conditions. Model accuracy is determined by model design and quality of input data. Model parameterisation is more challenging, because it requires detailed knowledge of physiological metrics in the proximal and distal circulations which may be inaccessible and variable in health and in disease [30].

In conclusion, the present is a hypothetical research in which we tried to elucidate the concept that anatomical structures; ESP and PP towards the etiopathogenesis of CGH with the help of real-life simulation. Our analysis by CFD proves both ESP and PP as contributing factors in the occurrence of CGH symptoms; preventive and therapeutic strategies should be initiated timely for CGH patient to improve their quality of life. CFD has been sparsely used by medical professionals; therefore, further researches should be encouraged in this domain to validate the presented hypothesis. 


\section{CONFLICT OF INTEREST}

No potential conflict of interest relevant to this article was reported.

\section{ORCID}

\author{
Aninditya Kaur \\ https://orcid.org/0000-0002-8811-4461 \\ N. Rakesh \\ https://orcid.org/0000-0003-4388-6334 \\ Sujatha S. Reddy \\ https://orcid.org/0000-0002-8648-2340 \\ Nithin Thomas \\ https://orcid.org/0000-0001-5487-1731 \\ Ravleen Nagi \\ https://orcid.org/0000-0002-0369-1383 \\ Deepa Jatti Patil \\ https://orcid.org/0000-0003-0077-8050
}

\section{REFERENCES}

1. Stovner Lj, Hagen K, Jensen R, et al. The global burden of headache: a documentation of headache prevalence and disability worldwide. Cephalalgia 2007;27:193-210.

2. Steiner TJ, Birbeck GL, Jensen RH, Katsarava Z, Stovner LJ, Martelletti P. Headache disorders are third cause of disability worldwide. J Headache Pain 2015;16:58.

3. Sjaastad 0, Bakketeig LS. Prevalence of cervicogenic headache: Vågå study of headache epidemiology. Acta Neurol Scand 2008;117:170-183.

4. Sjaastad 0, Fredriksen TA, Pfaffenrath V. Cervicogenic headache: diagnostic criteria. The Cervicogenic Headache International Study Group. Headache 1998;38:442-445.

5. Bogduk N. Cervicogenic headache: anatomic basis and pathophysiologic mechanisms. Curr Pain Headache Rep 2001;5:382-386.

6. Chuang WC, Short JH, McKinney AM, Anker L, Knoll B, McKinney ZJ. Reversible left hemispheric ischemia secondary to carotid compression in Eagle syndrome: surgical and CT angiographic correlation. AJNR Am J Neuroradiol 2007;28:143-145.

7. Oztunç H, Evlice B, Tatli U, Evlice A. Cone-beam computed tomographic evaluation of styloid process: a retrospective study of 208 patients with orofacial pain. Head Face Med 2014;10:5.

8. Watson DH, Trott PH. Cervical headache: an investigation of natural head posture and upper cervical flexor muscle performance. Cephalalgia 1993;13:272-284; discussion 232.

9. Chourdia V. Elongated styloid process (Eagle's syndrome) \& severe headache. Indian J Otolaryngol Head Neck Surg 2002;54:238-241.
10. Schilling J, Schilling A, Suazo Galdames I. Ponticulus posticus on the posterior arch of atlas, prevalence analysis in asymptomatic patients. Int J Morphol 2010;28:317-322.

11. Cakmak O, Gurdal E, Ekinci G, Yildiz E, Cavdar S. Arcuate foramen and its clinical significance. Saudi Med J 2005;26:14091413.

12. Wight S, Osborne N, Breen AC. Incidence of ponticulus posterior of the atlas in migraine and cervicogenic headache. J Manipulative Physiol Ther 1999;22:15-20.

13. Piagkou M, Anagnostopoulou S, Kouladouros K, Piagkos G. Eagle's syndrome: a review of the literature. Clin Anat 2009;22:545558.

14. Anbiaee N, Javadzadeh A. Elongated styloid process: is it a pathologic condition? Indian J Dent Res 2011;22:673-677.

15. Tambawala SS, Karjodkar FR, Sansare K, et al. Prevalence of ponticulus posticus on lateral cephalometric radiographs, its association with cervicogenic headache and a review of literature. World Neurosurg 2017;103:566-575.

16. Fredriksen TA, Fougner R, Tangerud A, Sjaastad O. Cervicogenic headache. Radiological investigations concerning head/neck. Cephalalgia 1989;9:139-146.

17. Morris PD, Narracott A, von Tengg-Kobligk H, et al. Computational fluid dynamics modelling in cardiovascular medicine. Heart 2016;102:18-28.

18. Fritsche G, Hueppe M, Kukava M, et al. Validation of a german language questionnaire for screening for migraine, tensiontype headache, and trigeminal autonomic cephalgias. Headache 2007;47:546-551.

19. Hong JP, Lai CH, Lin YC, Chou SW. Clinical assessment of patients with cervicogenic headache: a preliminary study. Chang Gung Med J 2010;33:58-66.

20. Ramadan SU, Gokharman D, Tunçbilek I, Kacar M, Koşar P, Kosar U. Assessment of the stylohoid chain by 3D-CT. Surg Radiol Anat 2007;29:583-588.

21. Fedorov A, Beichel R, Kalpathy-Cramer J, et al. 3D Slicer as an image computing platform for the Quantitative Imaging Network. Magn Reson Imaging 2012;30:1323-1341.

22. Hasan M, Shukla S, Siddiqui MS, Singh D. Posterolateral tunnels and ponticuli in human atlas vertebrae. J Anat 2001;199(Pt 3):339-343.

23. Bogduk N, Govind J. Cervicogenic headache: an assessment of the evidence on clinical diagnosis, invasive tests, and treatment. Lancet Neurol 2009;8:959-968.

24. Zito G, Jull G, Story I. Clinical tests of musculoskeletal dysfunction in the diagnosis of cervicogenic headache. Man Ther 2006;11:118-129.

25. de Andrade KM, Rodrigues CA, Watanabe PC, Mazzetto MO. Styloid process elongation and calcification in subjects with TMD: clinical and radiographic aspects. Braz Dent J 2012;23:443-450.

26. Wong KK, Wang D, Ko JK, Mazumdar J, Le TT, Ghista D. Computational medical imaging and hemodynamics framework for functional analysis and assessment of cardiovascular structures. Biomed Eng Online 2017;16:35.

27. Kristoffersen ES, Lundqvist C. Medication-overuse headache: epidemiology, diagnosis and treatment. Ther Adv Drug Saf 
2014;5:87-99.

28. Posadzki P, Ernst E. Spinal manipulations for cervicogenic headaches: a systematic review of randomized clinical trials. Headache 2011;51:1132-1139.

29. Jull GA, Stanton WR. Predictors of responsiveness to physio- therapy management of cervicogenic headache. Cephalalgia 2005;25:101-108.

30. Ohhara Y, Oshima M, Iwai T, et al. Investigation of blood flow in the external carotid artery and its branches with a new OD peripheral model. Biomed Eng Online 2016;15:16. 